\title{
A CERÂMICA VERMELHA E OS IMPACTOS SOCIOAMBIENTAIS EM UMA CIDADE NO INTERIOR DO RIO GRANDE DO NORTE
}

\author{
Sanclair Solon de Medeiros \\ sanclairfas@yahoo.com.br
}

\section{RESUMO}

O presente trabalho foi concebido com o objetivo de discutir sobre o processo produtivo da indústria de cerâmica vermelha e os impactos socioambientais decorrentes desse processo no município de Currais Novos com vistas a traçar uma relação entre meio ambiente, economia e impactos socioambientais. A metodologia utilizada consistiu de levantamento bibliográfico e aplicação de entrevistas estruturadas com proprietários e funcionários. Para definir o número de entrevistados utilizou-se o critério de saturação, pois consiste em determinar a realização de entrevistas até o momento em que não se obtenham dados novos que possam acrescentar discussões ao tema. Por fim, são apresentados os resultados que identificam os impactos socioambientais das cerâmicas citando as emissões atmosféricas, resíduos sólidos, baixa renda dos funcionários, equipamentos de segurança inadequados, doenças de ordem respiratória entre outros. São ainda sugeridas medidas para minimização destes impactos como forma de tornar a Indústria de Cerâmica Vermelha no município mais sustentável.

PALAVRAS-CHAVE: Indústria Ceramista, Meio Ambiente, Processos Produtivos.

\section{RED POTTERY INDUSTRY AND THE SOCIAL AND ENVIRONMENTAL IMPACTS ON A COUNTRYSIDE CITY OF RIO GRANDE DO NORTE STATE, BRAZIL}

\section{ABSTRACT}

This study was designed with the primary goal of identifying the production process of Red Poterry Industry and the social and environmental impacts resulting from this process in the countryside of Currais Novos, in order to treat a relationship between environment, economics and environmental impacts. The methodology used was to lay a literature review and application of interviews with owners and employees. To set the number of respondents used the criteria of saturation, as is determining the interviews so far as they
\end{abstract}

do not obtain new data that may add to the discussion. Finally, the results which have been presented identify the environmental impacts of the ceramic Industry citing a few such as atmospheric emissions, solid waste, low wages for employees, inadequate personal protection and safety equipment, respiratory illness among others. However there have been suggested measures to minimize these impacts as a way to make the Red Ceramic Industry in the municipality more sustainable.

KEYWORDS: Poterry Industry, Environmental, Production Process. 


\section{INTRODUÇÃO}

A Indústria de Cerâmica Vermelha (IVC) produz materiais de tipo tijolos (maciços e vazados), telhas e lajotas, que são utilizados na estruturação ou vedação do ramo da construção civil. Nessa indústria são utilizadas argilas do tipo massapé de teores de ferro maior do que $6 \%$, que apresentam cores avermelhadas durante a queima. (SUDENE, 1988)

Esse é um ramo industrial que advém da transformação da produção de cerâmica de ofício artesanal para indústria especializada com início em 1769, quando o empresário Josiah Wedgwood difundiu o uso de máquinas a vapor para triturar matérias-primas e para movimentar os tornos, em suas oficinas na Inglaterra. (NASCIMENTO, 2007)

A indústria de cerâmica vermelha emerge como um processo industrial que envolve os usos de argila e de lenha na produção de telhas e tijolos. Esse é um processo produtivo que tem em seu bojo a produção de aspectos e impactos sociais e ambientais.

Para o desvelamento deste trabalho, optou se por expor alguns aportes teóricos e conceituais fundamentais ao estudo em questão.

Neste estudo, impacto socioambiental está sendo entendido, segundo a Resolução CONAMA no. 01 de 1986, como:

\footnotetext{
"toda alteração das propriedades físicas, químicas e biológicas do meio ambiente, causada por qualquer forma de matéria ou energia resultante das atividades humanas que, direta ou indiretamente, afetam: a segurança e o bem-estar da população; as atividades sociais e econômicas; a biota; as condições estéticas e sanitárias do meio ambiente e a qualidade dos recursos ambientais." (CONAMA, 1986, p. 1)
}

Por sua vez, de acordo com ISO 14.001, impacto é qualquer modificação do meio ambiente, adversa ou benéfica, que resulte no todo ou em parte, das atividades, produtos ou serviços de uma organização (ABNT, 2004).

A partir dessa contextualização, coloca-se como questão central dessa pesquisa: que impactos socioambientais vêm sendo produzidos pela indústria de cerâmica vermelha no município de Currais Novos?

Assim, o presente trabalho visa discutir sobre o processo produtivo da indústria de cerâmica vermelha e os impactos socioambientais decorrentes desse processo no município de Currais Novos com vistas a traçar uma relação entre meio ambiente, economia e impactos socioambientais.

\section{REVISÃO BIBLIOGRÁFICA}

\subsection{O município de Currais Novos/RN}


O município está situado na microrregião do Seridó Oriental, com coordenadas - Latitude 6으 $15^{\prime} 39^{\prime \prime}$ Sul e Longitude 360 31' 04" Oeste. Tem área geográfica de 864,34 km², equivalendo a 1,64\% da superfície total do Estado. Com relação a capital se distancia em $172 \mathrm{~km}$, pela BR 304, tem seus limites geográficos ao norte com Lagoa Nova e Cerro Corá, ao sul tem-se Acari e o Estado da Paraíba, no leste Campo Redondo e São Tomé e a oeste os municípios de São Vicente e Acari. (IDEMA, 2007).

As cerâmicas no município de Currais Novos, no total de 4 (quatro), empregam atualmente 120 pessoas, tem suas principais atividades voltadas para a produção tijolos, telhas e lajotas.

$\mathrm{Na}$ esfera produtiva destas empresas uma quantidade de $32.000 \mathrm{~m}^{3}$ de argila, são gastos cerca de $R \$ 13.600,00$ com energia elétrica e, ainda, cerca de 1120 metros cúbicos estéreos de lenha são utilizados para suprir as necessidades de produção das mesmas durante um mês (um metro cúbico estéreo de lenha consiste em um metro cúbico de lenha desarrumado tendo em vista a não conformidade da estrutura da lenha).

\subsection{A cerâmica vermelha no Rio Grande no Norte}

A atividade econômica, denominada de indústria ceramista, constitui a tempos parte da economia do Rio Grande do Norte, a cerâmicas realmente não tem certa representatividade na economia regional com relação ao Produto Interno Bruto (PIB) do RN, porém mesmo com esta não representatividade o que se pode verificar nesse segmento é que o setor ceramista do Estado sempre tem se desenvolvido em novas áreas do seu território, assumindo novas dimensões, tanto tecnológicas quanto produtivas.

E com esse desenvolvimento, o número de empresas cresceu, a produção segue o mesmo ritmo, como também a comercialização e consequentemente a geração de empregos, e assim, mas não menos importante, os problemas ambientais: cita-se aqui a degradação da cobertura vegetal para ser usada como fonte energética através da queima e a degradação solo para extração de argila, contribuindo assim, para o surgimento de uma problemática que também será apresentada e discutida neste trabalho monográfico.

Um dos mais importantes retratos desta realidade é apresentado no estudo "O perfil da indústria de cerâmica vermelha no Rio Grande do Norte: uma síntese", destacando que

"no Rio Grande do Norte existe um parque cerâmico que abrange empresas produtoras de tijolos, telhas, lajotas, além de outros produtos. Estas empresas estão predominantemente localizadas na zona rural, concentradas nas proximidades de Natal, no vale do Rio Açu, e na região do Seridó. Além destes pontos, elas podem ainda ocorrer dispersas, em diversos municípios" (CARAVALHO, LEITE, REGO, 2001, p. 1).

E nesses três principais polos, a organização das empresas permite uma certa racionalização dos custos de produção. Conforme apresentou por Carvalho, Leite e Rego (2001), as cerâmicas no RN são organizadas juridicamente da seguinte forma: $55 \%$ são empresas da categoria Limitada 
(Ltda); 31\% são empresas individuais; $7 \%$ associações e os outros 7\% divididos entre Cooperativas e instituições sem personalidade jurídica.

Com essas organizações, esse segmento industrial tem sua significância baseada também na geração de empregos, nas regiões e cidades onde atuam, e assim fixam o homem à sua localidade de origem, evitando a mudança para a capital do Estado ou outras localidades (êxodo rural), segundo Carvalho, Leite e Rego (2001). Para esses autores, as cerâmicas tem empregado recentemente cerca de 5.494 trabalhadores.

Em relação aos insumos utilizados "o setor cerâmico do Estado consome mensalmente $106.497 \mathrm{~m} 3$ de lenha e $173.925 \mathrm{t}$ de argila, produz 82.799.000 de peças/mês, com predominância de telhas, seguida de tijolos, lajotas além de outros produtos, detém um consumo de energia elétrica que totaliza 2.500.000 kWh e desmata 37.384 ha./ano". (CARVALHO, LEITE, REGO 2001, p. 36).

No que tange a venda da produção das cerâmicas do Estado, a demanda da produção estadual dessa indústria, por setor da economia, se distribui da seguinte forma: um terço do que é produzido é destinado ao pequeno consumidor, um terço vai para os depósitos de vendas de produtos cerâmicos e um terço para as empresas do setor da construção civil. Em relação à demanda da produção seridoense, cerca de $97 \%$ de suas telhas são exportadas para os estados da Paraíba, Pernambuco, Alagoas, Sergipe e Bahia, enquanto que a produção do Vale do Açu é quase totalmente comercializada internamente, sendo apenas $20 \%$ vendida para outros estados. Já as peças fabricadas na Grande Natal são integralmente comercializadas dentro do próprio Estado.

\subsection{Impactos socioambientais}

Quando tratamos sobre a impactação ambiental e suas consequências rapidamente associamos, o termo em questão, a imagem de um rio totalmente poluído, fétido e verde, pensamos, ainda, em uma área devastada ou algo do tipo. Porém esses impactos podem ser ainda uma melhoria da qualidade de vida da população de uma área pelo recebimento de uma indústria de cerâmica vermelha, por exemplo, pode-se apresentar ainda a implantação de uma praça e assim tem-se uma nova nomenclatura desses impactos denominando-os como impactos socioambientais.

Em sua definição dada pela NBR ISO 14001, em seu item 3.4.1, o impacto ambiental é definido como qualquer modificação do meio ambiente, adversa ou benéfica, que resulte no todo ou em parte, das atividades, produtos ou serviços de uma organização. Porém, para um melhor entendimento do conceito deve-se apresentar a definição de meio ambiente como circunvizinhança em que uma organização opera, incluindo o ar, água, solo, recursos naturais, flora, fauna, seres humanos e suas interligações. (ABNT, 2004)

Tratando-se ainda da ISO 14001, e relacionando o seu conhecimento com a pesquisa nas cerâmicas observou-se que $100 \%$ dos proprietários conhecem ou já ouviram falar nesta normatização, resultado este que não é observado junto aos funcionários pois obteve-se que $100 \%$ destes desconhecem do que se trata a ISO.

Continuando a Resolução no 001/86 do Conselho Nacional de Meio Ambiente (CONAMA), em seu art. 1으, apresenta impacto ambiental como: 
"qualquer alteração das propriedades físicas, químicas e biológicas do meio ambiental causada por qualquer forma de matéria ou energia resultante das atividades humanas que, direta ou indiretamente, afetam a saúde, a segurança e o bem estar da população; a biota; as condições estéticas e sanitárias do meio ambiente e a qualidade dos recursos ambientais." (CONSELHO NACIONAL DO MEIO AMBIENTE, 1986, p.1).

Segundo Sachs (1993 apud COSTA, 2009), impacto ambiental é a alteração da qualidade ambiental quando ocorre modificação no meio ambiente pela ação humana.

Pode-se citar ainda que os impactos ambientais, tem amplitude local, regional ou global e dependendo de sua intensidade reparáveis ou não-reparáveis com duração de curta a longa. São caracterizados pela extensão, severidade, duração e modificação do meio ambiente sua problemática pode ainda ser justificada pela ocorrência natural ou não dos fatores que impactam sobre o meio.

Ainda, em concordância com a definição da NBR ISO 14001, podemos fazer uma relação com a classificação dos impactos em:

\footnotetext{
"Impacto Adverso: quando este representa uma mudança negativa ao meio ambiente, como por exemplo, esgotamentos dos recursos naturais renováveis e não renováveis e a contaminação do solo, da água e do ar, comprometimento da biodiversidade, erosões e compactações do solo, doenças e lesões, etc.;

Impacto Benéfico: quando este representa uma mudança positiva no meio ambiente, por exemplo: regenerações, redução de consumos, descontaminações, geração de riquezas, etc." (WATHERN, 1988).
}

Assim, os impactos ambientais podem ser classificados sem a presença do empreendimento proposto, com a situação decorrente de sua implantação, sendo adversos ou benéficos.

Sell (2006 apud COSTA, 2009) esclarece que há uma relação de causa e efeito entre aspectos e impactos, pois, um aspecto pode causar ou contribuir para mais de um impacto, e um dado impacto pode ser decorrente de diversos aspectos; por vezes, a combinação de aspectos gera efeitos (substâncias, ou condições propícias, por exemplo) que causam outros impactos específicos. Essas relações não são de todo conhecidas.

E com base nas explanações acima, observa-se que pode existir problemas quando da identificação de aspectos e impactos ambientais. A ISO 14001 define impacto ambiental como qualquer modificação do meio ambiente, adversa ou benéfica, que resulte, no todo ou em parte, dos aspectos ambientais da organização. Uma característica positiva da diferenciação entre aspecto e impacto ambiental adotada pela norma NBR ISO 14.001 é deixar claro que a emissão de um 
poluente não é um impacto ambiental. Impacto é alteração da qualidade ambiental que resulta dessa emissão. É a manifestação no receptor, seja este um componente do meio físico, biótico ou antrópico. Nas ações causadas pelo homem, os impactos são as consequências, enquanto os aspectos ambientais são os mecanismos ou os processos pelos quais ocorrem às consequências como, é exemplificado no quadro a seguir.

Tabela 1 - Exemplos de relações e atividade, aspecto e impacto ambiental

\begin{tabular}{l|l|l}
\hline \multicolumn{1}{c|}{$\begin{array}{c}\text { Atividade, Produto ou } \\
\text { Serviço }\end{array}$} & \multicolumn{1}{|c}{ Aspecto } & \multicolumn{1}{c}{ Impacto } \\
\hline $\begin{array}{l}\text { Atividade - Manuseio de } \\
\text { materiais perigosos }\end{array}$ & $\begin{array}{l}\text { Possibilidade de vazamentos para o } \\
\text { meio ambiente }\end{array}$ & $\begin{array}{l}\text { Contaminação da água } \\
\text { ou do solo }\end{array}$ \\
\hline $\begin{array}{l}\text { Produto - Projeto de um } \\
\text { veículo (ou componentes) }\end{array}$ & $\begin{array}{l}\text { Uso de matérias-primas esgotáveis } \\
\text { (água, metais, plásticos) }\end{array}$ & $\begin{array}{l}\text { Esgotamento } \\
\text { recursos naturais }\end{array}$ \\
\hline $\begin{array}{l}\text { Serviço - Operação de de } \\
\text { caminhões de transporte }\end{array}$ & Emissão de gases pelo escapamento & Contaminação do ar \\
\hline
\end{tabular}

Fonte: Moura, 2008, p.112

Após os considerandos apresentados, concluímos que há diferenças entre aspectos e impactos ambientais, sendo o primeiro representado pelas interfaces ou mecanismos entre uma causa (ação humana) e o segundo como sendo as consequências dessas ações.

\section{METODOLOGIA}

Para responder à questão central deste estudo, a metodologia adotada partiu primeiramente de revisões bibliográficas, por meio de consulta em periódicos, livros e documentos existentes na Prefeitura Municipal de Currais Novos, no Instituto Brasileiro de Geografia e Estatística (IBGE), no Instituto Federal de Educação Ciência e Tecnologia do Rio Grande do Norte (IFRN); na Agência de Desenvolvimento Sustentável do Seridó (ADESE) e outras bases de dados.

Em seguida, foi realizada uma pesquisa de campo, por meio da aplicação de uma entrevista estruturada, contendo questões abertas e fechadas, junto aos quatro proprietários e a vinte e três trabalhadores das indústrias de cerâmica vermelha desse município. Esse número de entrevistados foi definido seguindo o "critério de saturação" esse critério consiste em realizar entrevistas até o momento em que não se obtenham dados novos que possam acrescentar discussões ao tema da pesquisa. (BERTAUX, 1980)

A pesquisa foi realizada nas quatro cerâmicas existentes, posteriormente, se tabulou os dados coletados por ocasião da entrevista. Tendo em vista que, conforme propõe Lakatos e Marconi (2007), faz-se necessária justamente a abordagem exploratória, descritiva e relacional entre impactos ambientais e sociais com vistas a observação do referido tema.

\section{RESULTADOS E DISCUSSÕES}




\subsection{Caracterização das cerâmicas do município de currais novos}

Para se apresentar uma caracterização das cerâmicas desse município, utilizou-se a entrevista estruturada aplicada com os empresários para se identificar o perfil de cada cerâmica que atua no município de Currais Novos.

A seguir apresentam-se os principais dados das mesmas.

Tabela 2 - Apresentação dos Dados Jurídicos e Número de Funcionários das Cerâmicas de Currais Novos

\begin{tabular}{l|l|l|l|c|c}
\hline \multicolumn{1}{c|}{ Cerâmica } & \multicolumn{1}{|c|}{$\begin{array}{c}\text { Organização } \\
\text { jurídica }\end{array}$} & Porte & Tipo & $\begin{array}{l}\text { Quantidade de } \\
\text { Funcionários }\end{array}$ & $\begin{array}{c}\text { Funcionário } \\
\text { Registrados }\end{array}$ \\
\hline Luciano Ltda. & $\begin{array}{l}\text { CNPJ + Contrato } \\
\text { Social }\end{array}$ & Micro & Limitada & 42 & 35 \\
\hline Totoró Ltda. & $\begin{array}{l}\text { CNPJ + Contrato } \\
\text { Social }\end{array}$ & Micro & Limitada & 24 & 24 \\
\hline Maniçoba & Sem registro & -- & -- & 20 & 20 \\
\hline $\begin{array}{l}\text { Currais Novos } \\
\text { Ltda. }\end{array}$ & $\begin{array}{l}\text { CNPJ + Contrato } \\
\text { Social }\end{array}$ & Micro & Limitada & 30 & 30 \\
\hline
\end{tabular}

Fonte: Autor

Pode-se verificar acima que 3 das 4 cerâmicas do município possuem caracterização empresarial sendo registradas e dotadas de Cadastro Nacional de Pessoa Jurídica (CNPJ) como também do Contrato Social que é exigido para o registro da empresa junto aos órgãos responsáveis (Junta Comercial do Estado do Rio Grande do Norte - JUCERN). O número de funcionário no total chega a 116 funcionários diretos e destes 109 possuem registro em carteira de trabalho o que demonstra uma preocupação das empresas pela legalização dos funcionários.

Tabela 3 - Apresentação dos Dados Financeiros das Cerâmicas de Currais Novos

\begin{tabular}{l|l|l|l|l}
\hline \multicolumn{1}{c|}{ Cerâmica } & Arrecadação anual & \multicolumn{1}{|c|}{$\begin{array}{c}\text { Folha de } \\
\text { pagamentos }\end{array}$} & \multicolumn{1}{c|}{ FGTS } & \multicolumn{1}{c}{ INSS } \\
\hline Luciano Ltda. & $\mathrm{R} \$ 300.000,00$ & $\mathrm{R} \$ 12.000,00$ & $\mathrm{R} \$ 600,00$ & $\mathrm{R} \$ 400,00$ \\
\hline Totoró Ltda. & $\mathrm{R} \$ 180.000,00$ & $\mathrm{R} \$ 12.000,00$ & $\mathrm{R} \$ 850,00$ & $\mathrm{R} \$ 700,00$ \\
\hline Maniçoba & $\mathrm{R} \$ 40.000,00$ & $\mathrm{R} \$ 9.000,00$ & -- & -- \\
\hline Currais Novos Ltda. & $\mathrm{R} \$ 200.000,00$ & $\mathrm{R} \$ 10.000,00$ & $\mathrm{R} \$ 700,00$ & $\mathrm{R} \$ 435,00$ \\
\hline
\end{tabular}

Fonte: Autor

No quesito arrecadação anual e de impostos verifica-se que existe diferenças no que tange o número de funcionários e a renda recebida por cada um, fazendo-se um cálculo simples e tendo em vista o valor dos salários informados pelos entrevistados observa-se que o valor da folha de pagamentos informadas pelos proprietários não condiz com o número de funcionários registrados. Ainda com relação aos impostos como o IPI, ICMS e outros as empresas que possuem registro CNPJ são optantes pelo Simples Nacional o que reduz a carga tributária destas. 
Tabela 4 - Apresentação dos itens produzidos pelas Cerâmicas de Currais Novos

\begin{tabular}{l|c|c|c}
\hline \multirow{2}{*}{ Cerâmica } & \multicolumn{3}{|c}{ Produtos } \\
\cline { 2 - 4 } & Telhas & Tijolos & Lajotas \\
\hline Luciano Ltda. & $\mathrm{X}$ & $\mathrm{X}$ & $\mathrm{X}$ \\
\hline Totoró Ltda. & & $\mathrm{X}$ & $\mathrm{X}$ \\
\hline Maniçoba & & $\mathrm{X}$ & $\mathrm{X}$ \\
\hline Currais Novos Ltda. & $\mathrm{X}$ & $\mathrm{X}$ & \\
\hline
\end{tabular}

Com relação a produção de itens as cerâmicas do município trabalham com os principais produtos que podem ser fabricados com a argila, citando as telhas, os tijolos e as lajotas. Observouse nas entrevistas realizadas que o tijolo é o carro chefe da produção das cerâmicas sendo este distribuído para estados como Sergipe, Pernambuco e Alagoas. Na cerâmica Totoró por exemplo somente $10 \%$ da produção é vendida para o RN o restante é totalmente vendido para outros estados.

Sendo assim, e de acordo com o apresentado acima os empresários e funcionários foram questionados sobre os impactos socioambientais que as cerâmicas ocasionam, um resumo dos resultados é apresentado nas tabelas a seguir.

Tabela 5 - Apresentação das respostas dos empresários sobre os impactos ambientais

\begin{tabular}{c|c|c|c|c}
\hline \multirow{2}{*}{ Cerâmicas } & \multicolumn{4}{|c}{ Impactos ambientais } \\
\cline { 2 - 5 } & Queima & $\begin{array}{c}\text { Resíduos } \\
\text { sólidos }\end{array}$ & $\begin{array}{c}\text { Emissões } \\
\text { atmosféricas }\end{array}$ & $\begin{array}{c}\text { Poluição } \\
\text { sonora }\end{array}$ \\
\hline A & $\mathrm{X}$ & $\mathrm{X}$ & $\mathrm{X}$ & Não tem \\
\hline B & Não tem & Não tem & $\mathrm{X}$ & Não tem \\
\hline C & Não tem & Não tem & $\mathrm{X}$ & Não tem \\
\hline D & Não tem & Não tem & $X$ & $X$ \\
\hline
\end{tabular}

Fonte: Autor

O quadro acima apresenta os tipos de impactos ambientais que são gerados em decorrência do processo produtivo acarretado pelas Cerâmicas no município de Currais Novos, um fato que merece destaque aqui é justamente quando os proprietários são questionados sobre esta impactação, não assumirem que todos os impactos citados acima são produzidos pelas suas empresas. Por exemplo, os resíduos sólidos gerados como cacos e aparas de argila não são produzidos pelas suas empresas. 
Tabela 6 - Apresentação das respostas dos funcionários das cerâmicas quando questionados sobre os impactos ambientais da atividade

\begin{tabular}{c|c|c|c}
\hline \multicolumn{4}{c}{ Impactos ambientais } \\
\hline Queimada & Sólidos & Atmosféricos & Sonoro \\
\hline $22 \%$ & $61 \%$ & $96 \%$ & $39 \%$ \\
\hline \multicolumn{4}{c}{ Fonte: Autor }
\end{tabular}

Pode-se assim, de acordo com o apresentado, que existe por parte dos empresários certo "desconhecimento" quando se trata sobre os impactos ambientais negativos da atividade ceramista no município, pois todos estes espaços foram visitados e constatou-se que estes tipos de impactos estão presentes em todas as cerâmicas. A questão dos resíduos sólidos, queima e emissões atmosféricas é uma das mais preocupantes tendo em vista que grandes quantidades de resíduos, lenhas e barulho são emitidos pelas cerâmicas no município de Currais Novos.

\subsection{Trabalho nas Cerâmicas}

A apresentação deste capítulo considera o trabalho nas cerâmicas como sendo item indispensável para o crescimento da atividade no município tendo em vista o desenvolvimento da atividade que é realizada pelo trabalho "braçal" dos seus atores com vistas a continuidade de todas as atividades produtivas das cerâmicas e mesmo assim com maquinários de certa forma "atuais" se fazem necessárias a presença do homem e sua força para amassar o barro e a partir daí ter o seu produto final, tijolos e telhas, acabados e sendo vendidos para a construção de casas e outros empreendimentos.

Tabela 7 - Perfil dos funcionários entrevistados

\begin{tabular}{c|c}
\hline Caracterização dos funcionários & Resultados \\
\hline Sexo & $100 \%$ do sexo Masculino \\
\hline Casados & $82 \%$ \\
\hline Idade Média dos respondentes & 40 anos \\
\hline Tempo de serviço média nas empresas & 4 pessoas \\
\hline Composição média da Família & Maioria dos casos somente o entrevistado \\
\hline Familiares trabalhando & $13 \%$ Analfabeto \\
\hline Escolaridade & $26 \%$ Ensino Fundamental \\
& 48\% Ensino Fundamental Incompleto \\
\hline Moradia & $91 \%$ tem casa própria \\
\hline
\end{tabular}

Fonte: Autor

Fazendo-se uma análise do quadro acima se pode visualizar que todos os funcionários das cerâmicas são do sexo masculino o que se justifica pelo "peso" do trabalho que tem que ser realizado como o enchimento do caixão alimentador, o carregamento de grandes pesos de produtos 
crus e queimados, a distribuição de material no pátio de secagem ou ainda as altas temperaturas que devem ser enfrentadas nos fornos ou estufagem.

Em média a idade dos funcionários está na casa dos 40 anos e a maioria destes é casado (82\%) tendo ainda uma média familiar 4 pessoas por residência caracterizadas pelo tipo tradicional de família pai, mãe e filhos. Esse tamanho familiar conforme apresentado acima é "arrimado" pelo genitor que de acordo com os resultados da pesquisa realizada normalmente é só ele quem trabalha na casa.

A escolaridade dos funcionários é algo que é característico para esse tipo de atividade conforme apresentado por Carvalho, Leite e Rego (2001) cerca de $88 \%$ dos funcionários de cerâmicas no estado estão entre analfabetos ou com o primeiro grau terminado. Nas cerâmicas de Currais Novos a realidade não é outra $87 \%$ dos entrevistados estão na mesma situação supraapresentada.

Uma informação que chamou atenção quanto a entrevista realizada foi a questão de que 91\% dos entrevistados possuem casa própria e citaram informalmente que foi conseguida com o "suor" do dia-a-dia do trabalho nas cerâmicas.

Com relação a jornada de trabalho, a mesma geralmente, começa às 6 horas, seguindo até as 17 horas ou em alguns casos até as 18 horas, dependendo da produção do dia a ser atingida principalmente dos funcionários responsáveis pela queima e pelo forno ${ }^{1}$.

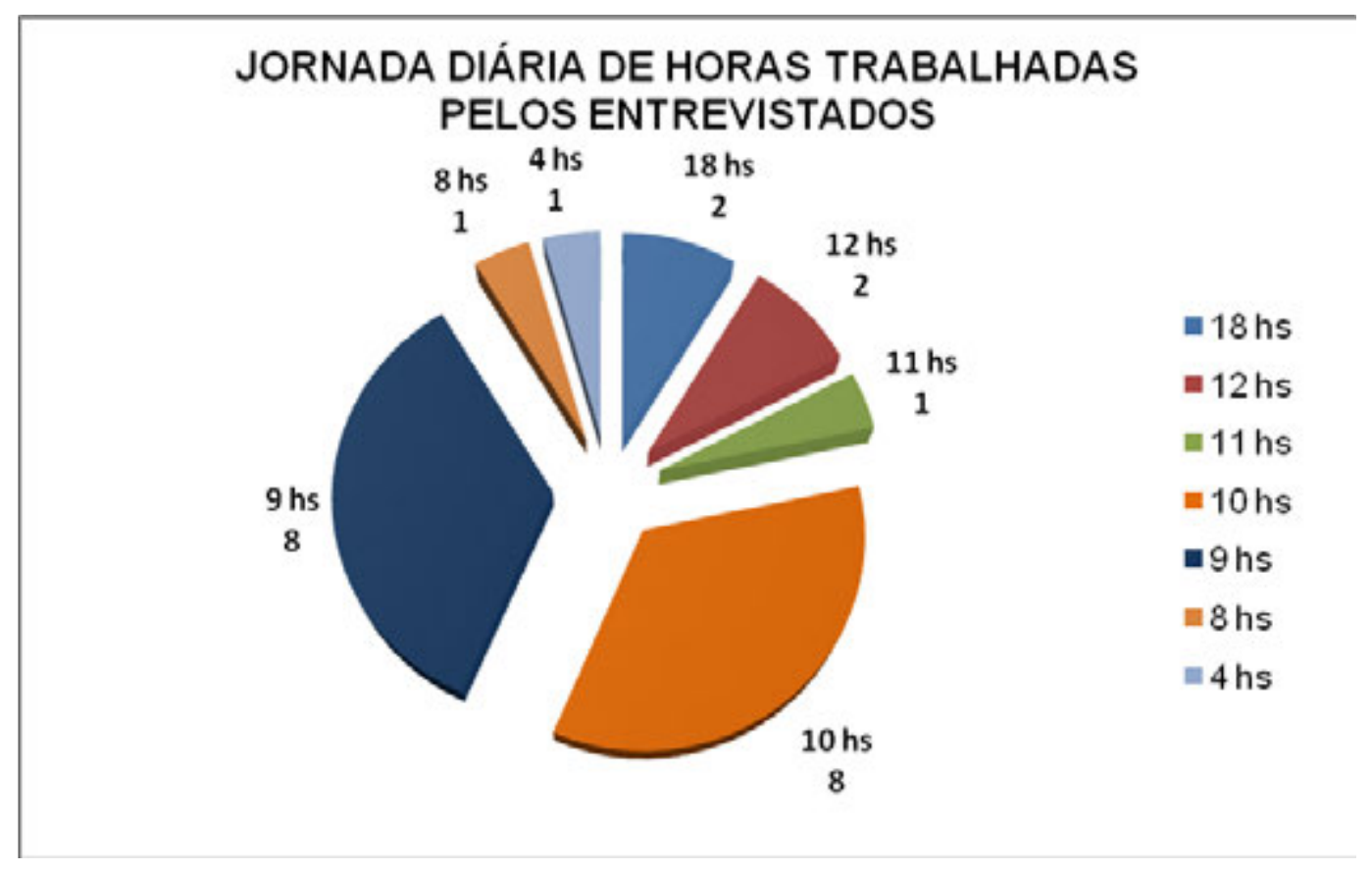

Figura 1 - Apresentação da Jornada Diária de Trabalho dos Entrevistados

\footnotetext{
${ }^{1}$ O funcionário designado como "forneiro" é aquele responsável por colocar e retirar telhas do forno, as quais deverão ser queimadas. Além dessa atividade, também carrega os caminhões que transportarão as telhas. Já o "queimador" é encarregado de alimentar os fornos com a lenha. Enquanto tiver lenha para queimar, ele estará lá.
} 
Uma característica que se faz presente no dia-a-dia desses trabalhadores é a falta de equipamentos de proteção, sejam esses individuais ou de grupo, citando-se como exemplo os capacetes, botas e luvas pelo menos. Fato esse que é explicado pela falta de incentivo ou ainda pela falta de educação de segurança do trabalho dos referidos trabalhadores. Os que os possuem normalmente têm seus equipamentos em estado precário de conservação o que não favorece a segurança do mesmo.

Tabela 8 - Itens de Segurança do Trabalho utilizados pelos funcionários

\begin{tabular}{c|c|c|c|c|c}
\hline \multicolumn{6}{c}{ Itens de Segurança utilizados pelos funcionários } \\
\hline Capacete & Auricular & Óculos & Luvas & Máscara & Bota \\
\hline $4 \%$ & $9 \%$ & $0 \%$ & $35 \%$ & $9 \%$ & $83 \%$ \\
\hline \multicolumn{7}{c}{ Fonte: Autor }
\end{tabular}

A apresentação acima mostra os percentuais dos funcionários pesquisados que utilizam equipamentos de segurança no trabalho. Registra-se aqui que todos que responderam que usavam botas realmente as estavam usando, todavia com relação aos outros itens mencionados, nenhum dos respondentes os usavam no momento da entrevista, que foi realizada durante um dia normal de atividades de todas as cerâmicas. Outro dado que vai de encontro ao respondido pelos funcionários e que esse mesmo questionamento foi realizando junto aos proprietários que informaram em alguns casos que seus funcionários utilizam itens de segurança como máscaras e não foi o verificado por ocasião da visita in loco realizada.

Nesse cenário, os acidentes são inevitáveis, ocorrem cortes, pancadas e ainda queimaduras.

O sol também é um fator agravante nas condições de trabalho, pela sua característica, o Seridó norte-rio-grandense tem muitas horas de insolação, observa-se somente o uso de chapéus e bonés e nenhum outro equipamento de combate aos raios ultravioletas, cita-se ainda que devido às altas temperaturas encontradas na atividade parte dos funcionários deste tipo de atividade não usavam camisas o que favorece o aparecimento de manchas e problemas cutâneos como os carcinomas ${ }^{2}$.

Tabela 9 - Apresentação das Doenças e Acidentes dos Funcionários da Cerâmicas de Currais Novos

\begin{tabular}{c|c}
\hline Doenças / acidentes & Quantidade \\
\hline Gripes constantes & 6 \\
\hline Dores nas costas (Lombalgia) & 3 \\
\hline Pneumonia & 1 \\
\hline Infecções & 1 \\
\hline Hérnias & 1 \\
\hline Queimaduras & 1 \\
\hline Total & 13 \\
\hline
\end{tabular}

\footnotetext{
${ }^{2}$ Carcinomas são todos os tipos de câncer.
} 
Em todas as cerâmicas pesquisadas observou-se que a gripe é uma doença constante entre os funcionários, todos relataram que devido a poeira, umidade e altas temperaturas são acometidos por gripes. Com relação aos outros tipos de doenças essas já são menos frequentes como também o índice de acidentes de trabalho, sendo nesta pesquisa registrado somente um acidente grave que foi relatado por um entrevistado quando estava realizando a função de estufeiro ${ }^{3}$ uma das estantes de aço caiu sobre ele queimando toda a lateral do pescoço. O referido funcionário possui 6 anos de experiência na função.

Além dos problemas citados, também existe a poluição sonora causada pelas maquinas e também dos veículos que trafegam entre a área da cerâmica. As máquinas ligadas proporcionam barulhos intensos, o que pode levar a alguns problemas auditivos, já que não se observa equipamentos de proteção para preveni-los.

Em decorrência do barro seco, existe muita poeira no local da cerâmica, entretanto não há o uso de máscaras que diminuam o contanto com as partículas que se encontram na atmosfera. Fazendo-se uma comparação com as minas de carvão em outros países onde existe devido a estas partículas um mal chamado de pulmão negro que tem como efeito a redução da capacidade de oxigenação e por fim a morte do indivíduo.

Além desses aspectos citados, deve ser lembrado que os trabalhadores estão constantemente deslocando grandes pesos e seus salários são consideravelmente baixos para as diversas atividades físicas que desenvolvem.

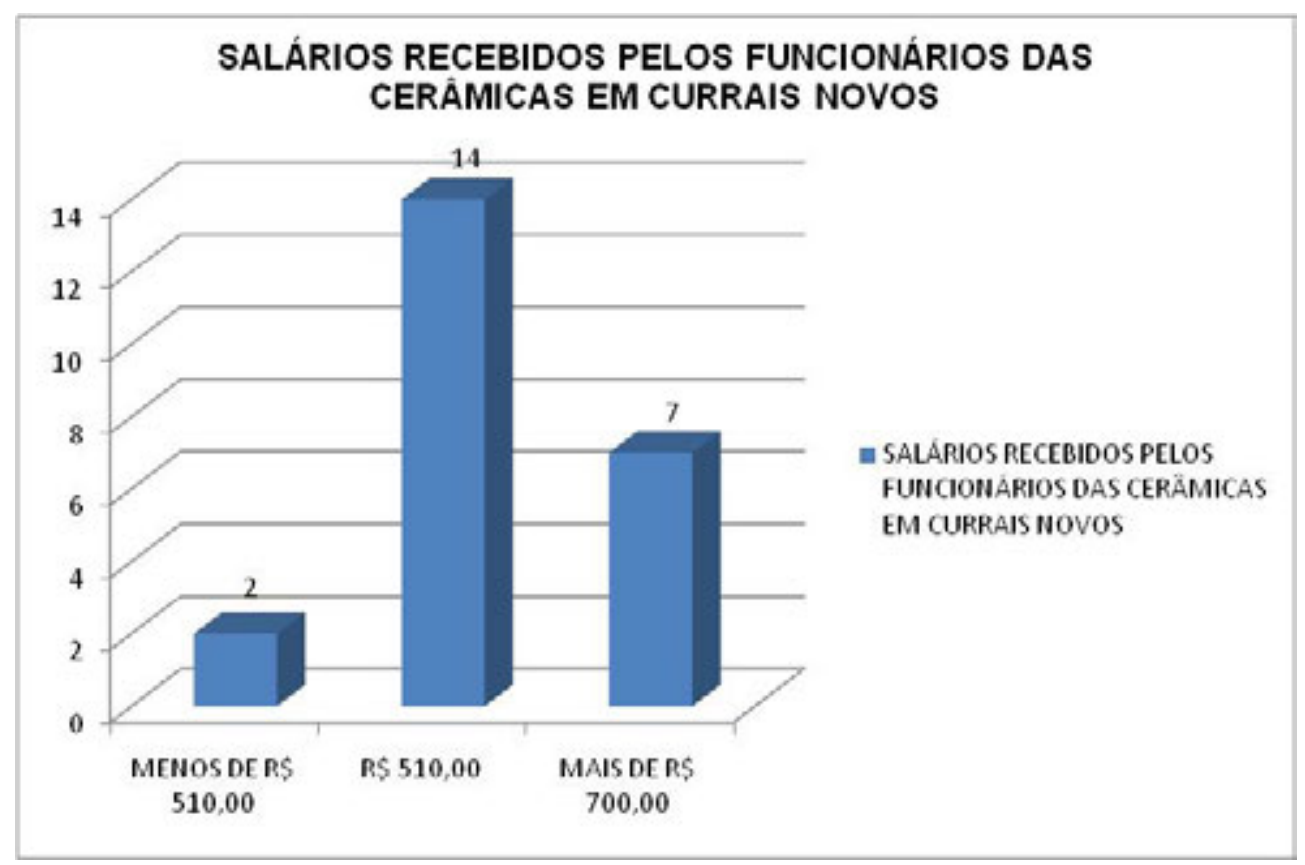

Figura 2 - Apresentação dos salários recebidos pelos entrevistados

\footnotetext{
${ }^{3}$ O Estufeiro é o responsável, em algumas cerâmicas pelo aquecimento inicial das peças após a secagem para aumentam a resistência e retirada da umidade das mesmas.
} 
Observa-se, ainda, a inexistência de programas de prevenção de acidentes neste tipo de empresa no município de Currais Novos com vistas a sensibilização de proprietários e funcionários.

Em si tratando ainda de impactos pode-se observar que existe uma grande quantidade de entulho em decorrência do processo produtivo, cita-se aqui os cacos e materiais que não foram aproveitados após a queima, fato este que gera entulhos nas áreas de entorno das cerâmicas.

Com relação a lenha que é utilizada na queima, os proprietários informaram que a mesma é advinda do município, não sendo necessários ainda a aquisição de lenha em outras cidades ou estados. Todavia, essa grande retirada de lenha não é reposta ou replantada pelas cerâmicas o que certamente acarretará uma aceleração do processo de desertificação do município, pois entendese desertificação como sendo a degradação das terras nas zonas áridas, semiáridas e sub-úmidas secas, resultante de vários fatores, incluindo as variações climáticas e as atividades humanas (ONU, 1997). Acrescenta-se ainda que a retirada de argila da área de leitos de rios e outros locais pode acarretar ainda o assoreamento de mananciais ou ainda o carreamento de grande quantidade de material que deveria estar firme tendo em vista que para a retirada de argila são feitas grandes crateras com este fim.

\section{CONSIDERAÇÕES FINAIS}

O trabalho ora apresentado realizou-se no ano de 2010 objetivando uma pesquisa sobre os impactos socioambientais das cerâmicas no município de Currais Novos/RN, permitindo uma adequada visualização do processo produtivo dessa atividade econômica com o intuito de apresentar dados, resultados e análises sobre o referido tema e assim algumas considerações passam a permear essa análise com vistas a também poder contribuir para o desenvolvimento sustentável da atividade ceramista objetivando reduzir os danos ambientais relacionados.

A totalidade das cerâmicas de Currais Novos foi pesquisada, e somente uma delas possui o licenciamento ambiental registrado junto ao IDEMA.

No que tange os impostos a serem recolhidos pela atividade 3 das 4 cerâmicas possuem registro e fazem a arrecadação de impostos como o FGTS, INSS e ICMS. Arrecadação esta que contribui para o desenvolvimento dos empregados com vistas a garantias trabalhistas e principalmente para a aposentadoria dos mesmos.

O processo produtivo das cerâmicas é composto de várias fases e se torna complexo, tendo em vista a quantidade de etapas que se fazem presentes, conforme apresentado anteriormente por meio do fluxograma. Porém, os ceramistas procuram trabalhar da forma mais simples possível sem buscar a evolução tecnológica ou o aprimoramento técnico. Essa falta de tecnologia como também de técnicas adequadas para a atividade ceramista impacta negativamente sobre as jazidas de argila como também de lenha, esta última que por sua vez está reduzindo suas quantidades favorecendo também o aumento da desertificação.

Na realidade falta também para todas as cerâmicas a elaboração de Planos de Manejo para as atividades que degradem o meio ambiente como também de autorização do Departamento Nacional de Produção Mineral para a extração de argila. 
Com isto podem ser sugeridas na busca de um melhor desenvolvimento da atividade ceramista de Currais Novos as seguintes atividades:

- Reflorestamento de áreas degradadas com espécies nativas ou frutíferas;

- Elaboração de plano de manejos florestais;

- Incentivo ao uso de outros materiais para queima nos fornos como o côco ou bagaço de cana ou ainda o gás natural.

Iniciando o processo produtivo tem-se o estoque de matérias prima e a movimentação deste material seco com isso são levantadas grandes quantidades de poeira, fato este que poderia ser amenizado com o plantio de árvores ou muro de contenção no entorno tendo em vista que esse material particulado é deslocado pelo vento para outras áreas podendo acarretar irritações, doenças respiratórias ou dependendo da localização da cerâmica bloquear a visão de motoristas.

O uso de água e energia são necessários ao processo produtivo. A água por sua vez é normalmente retirada de poços particulares e não é utilizada em quantidade exagerada em razão de que é somente para umedecer a argila a ser laminada. Como o poço não possui registro de outorga, recomendamos as empresas procurarem se regularizar através da Secretaria Estadual de Meio Ambiente e Recursos Hídricos (SEMARH).

Já para a energia elétrica os gastos são relativamente altos e tendo em vista a precariedade da rede de distribuição da cidade pode ocorrer sobrecarga na rede tendo em vista o maquinário pesado que é utilizado pelas cerâmicas.

No processo de secagem os aspectos identificados de forma significativa foram, a não utilização de EPI's pelos empregados e a perda de matérias-primas através de dispersão devido a peças que trincam e quebram com o transporte até o local de secagem. Para evitar lesões na pele e câncer em longo prazo, propomos a utilização, pelos empregados, de protetores solar, roupas e acessórios adequados como, chapéus, camisas ou macacões que cubram os braços e a parte do dorso. Para evitar uma maior retirada de argila dos leitos de rios e açudes da região, provocando assim, erosões, assoreamento dos rios e a diminuição das margens e desperdício de recursos naturais, propomos um melhor controle de qualidade na utilização da argila e o transporte dos produtos cerâmicos ao local da secagem.

O processo da queima é a etapa onde ocorrem os maiores aspectos e impactos significativamente identificados. As emissões atmosféricas, os resíduos sólidos, as cinzas e fuligens e a não utilização de EPI's pelos empregados, são os aspectos significativamente identificados nesse processo. Para evitar impactos como, poluição do ar, desperdício de matéria-prima, incômodo à vizinhança, problemas respiratórios, queimaduras de 1으, 2ำ e 3으 grau, lesões e até morte sugere-se assim as seguintes atividades:

- Instalação de equipamentos de depuração de gases;

- Controle de emissão de partículas por equipamento de aspiração e separação;

- Umedecimento de áreas de circulação e áreas de sazoneamento antes da movimentação de matérias-primas;

- Uso do gás natural, possibilitando a queima completa e a emissão de menos poluentes. 
Mesmo com a simplicidade praticada no processo produtivo vê-se um significativo número de resíduos sólidos gerados. Para isto sugere-se para minimização destes impactos as seguintes atividades:

- Aproveitamento do material cru para retorno ao caixão alimentador para produção de novos produtos;

- O material queimado em caco ou fora dos padrões para venda podem ser reaproveitados para aterros e baldrames de casas como metralha;

- As cinzas que restam da queima da madeira podem ser utilizadas como composto de adubo para a vegetação local;

- Implantação de laboratórios de análises de materiais prontos para avaliar a qualidade da argila utilizada e também dos produtos cerâmicos.

Para os trabalhadores e suas atividades laborais a utilização de EPI's é uma necessidade visível tendo em vista que a maioria deles não os utiliza excetuando-se as botas. Esses aspectos podem provocar impactos significativos como, surdez e mutilação dos membros superiores e o incômodo à vizinhança, respectivamente. Para evitar esses possíveis impactos propomos a utilização dos equipamentos como, protetores auriculares e roupas adequadas, tipo macacão. Abafadores nos equipamentos que produzem ruídos e manutenção adequada e com freqüência nos equipamentos, para evitar ruídos e incômodo à vizinhança. Treinamento com os empregados que trabalham na área de extrusão das peças cerâmicas, em relação à manipulação da extrusora e dos equipamentos que trazem riscos como, mutilação.

A identificação também fornece a informação de que, além dos planos de atendimento às emergências é necessário considerar todos os cuidados para eliminar estes riscos.

Com relação à NBR ISO 14001 no que se refere o conhecimento desta norma pelos proprietários e empregados os proprietários em sua maioria conhecem a norma porém não a aplicam, já os empregados $100 \%$ não conhecem ou nunca ouviram falar na referida norma.

Por fim, esta pesquisa mostrou que a indústria de cerâmica vermelha tem impactos socioambientais próprios que podem, ao longo do tempo, tornar insustentável o processo produtivo das cerâmicas vermelhas locais, tendo em vista que são necessárias uma série de adaptações objetivando um melhor aproveitamento do setor no que tange a melhoria da qualidade de vida de seus funcionários e principalmente do meio ambiente atingido pelas indústrias de cerâmicas vermelha de Currais Novos.

Finalizando, utilizo-me das palavras de Silva (2007), citando que tudo isso se constitui em problemas socioambientais, e não se consegue separar cartesianamente natureza-sociedade desse processo de produção, pois trata-se de uma relação homem-natureza e uma relação do homem com o homem e, ao mesmo instante, da natureza consigo mesma, porque entende-se que o homem também é natureza. É assim que procuramos não tomar homem e natureza como pólos excludentes, mas como elementos que convivem em constante interação na busca da construção e reconstrução do território, possibilitando daí a atualização da problemática que decorre entre ambos. 


\section{REFERÊNCIAS}

ANDRADE, Manuel Correia de. 0 minério de tungstênio no nordeste do Brasil. Mossoró: FUNDAJ/CNPQ, 1990.

ASSOCIAÇÃO BRASILEIRA DE NORMAS TÉCNICAS: NBR 14001: sistemas de gestão ambiental especificação e diretrizes para uso. Rio de janeiro: 2004.

BERTAUX, Daniel. L'approche biografique: as validité méthodologique, ses potentialités. Caries Internationaux de Sociologie, V. LXIX, p. 45-67. 1980.

BOUTH, Jorge Alberto Cardoso. Manual de operações básicas na indústria de cerâmica vermelha. Natal: Fastgraf, 2008.

BRASIL. Resolução CONAMA 001, de 23 de janeiro de 1986. Dispõe sobre as diretrizes gerais para uso e implementação da Avaliação de Impacto Ambiental como um dos instrumentos da Política Nacional do Meio Ambiente. Diário Oficial da República Federativa do Brasil. Brasília, DF 17 fev 1986.

BRASIL. Resolução CONAMA 357, de 17 de março de 2005. Dispõe sobre a classificação dos corpos de água e diretrizes ambientais para o seu enquadramento, bem como estabelece as condições e padrões de lançamento de efluentes, e dá outras providências. Diário Oficial da República Federativa do Brasil. Brasília, DF 17 mar 2005.

CARSON, R. Silent spring. Greenwich: Fawcett, 1962.

CARVALHO, O. de C; LEITE, J. Y. P; REGO, J. M. do. Perfil industrial da cerâmica vermelha no Rio Grande do Norte: uma síntese. Natal: FIERN/SENAI, 2001.

COSTA, Rafael Fonseca da. Aspectos e impactos ambientais da cerâmica Nossa Senhora das Vitórias em Carnaúba dos Dantas/RN. Monografia- Instituto Federal de Educação Ciência e Tecnologia do Rio Grande do Norte.

INSTITUTO DE DESENVOLVIMENTO SUSTENTÁVEL E DEFESA DO MEIO AMBIENTE. Perfil do município: Currais Novos, 2007. Rio Grande do Norte. Disponível em: <www.idema.rn.gov.br>. Acesso em 10 fev. 2010.

MARCONI, Marina de Andrade; LAKATOS, Eva Maria. Fundamentos da metodologia científica. 6 ed. São Paulo: Atlas, 2007.

MARCONI, Marina de Andrade; LAKATOS, Eva Maria. Metodologia científica. 5 ed. São Paulo: Atlas, 2007.

MONTEIRO, Denise Mattos. Terra e trabalho na história: estudos sobre o Rio Grande do Norte. Natal: UFRN, 2007.

MOURA, Luiz Antônio Abdalla de. Qualidade e gestão ambiental. 5 ed. São Paulo: Juarez de Oliveira, 2008.

NASCIMENTO, Waldécio Sávio dos Anjos do. Avaliação dos impactos ambientais gerador por uma indústria cerâmica típica da Região do Seridó/RN. Dissertação (Mestrado em Engenharia Mecânica)- Universidade Federal do Rio Grande do Norte. Disponível em <www.bczm.ufrn.br>. Acesso em: 15 mar. 2010. 
PIMENTA, Handson Cláudio Dias; GOUVINHAS, Reidson Pereira. Ferramentas de gestão ambiental. Natal: CEFET/RN, 2008.

SILVA, Valdenildo Pedro da. Impactos ambientais da expansão da cerâmica vermelha em Carnaúba dos Dantas/RN. Revista Holos, Natal, ano. 23, v. 3, p. 96-112, dez. 2010. Disponível em: < http://www2.ifrn.edu.br/ojs/index.php/HOLOS/article/viewFile/133/121>. Acesso em: 7 mar. 2010.

SOUZA, Joabel Rodrigues da. Totoró, berço de Currais Novos. Natal: UFRN, 2008.

SUDENE. Conservação de energia no setor industrial: cerâmica vermelha estrutural. Recife: Sudene, 1988.

WATHERN, P. Avaliação de impacto ambiental: teoria e prática. Unwin Hyman: Londres, 1988.

ONU,1997, Convenção das Nações Unidas de Combate à Desertificação. Brasília: Ministério do Meio Ambiente, dos Recursos Hídricos e da Amazônia Legal, 1997. 89p. 